Original Article (short paper)

\title{
Lifestyle of school-aged children with and without developmental coordination disorder
}

\author{
Jorge Lopes Cavalcante Neto ${ }^{1,2}$ (D), Liz Araújo Rohr ${ }^{1}$ (D), Ana Cristina Cardoso da Silva ${ }^{3}$ (D), \\ Amanda Garcia de Godoy ${ }^{1}$ (D), Eloisa Tudella ${ }^{1}$ \\ 'Universidade Federal de São Carlos, Departamento de Fisioterapia, São Carlos, SP, Brasil. \\ ${ }^{2}$ Universidade do Estado da Bahia, Departamento de Ciências Humanas, Jacobina, BA, Brasil. \\ ${ }^{3}$ Universidade Federal de São Carlos, Departamento de Terapia Ocupacional, São Carlos, SP, \\ Brasil.
}

\begin{abstract}
Aim: To analyze the association between lifestyle and signs of DCD in children aged 7 to 10 . Methods: A total of 93 schoolchildren aged 7 to 10 were recruited for this study. Developmental Coordination Disorder Questionnaire (DCDQ), Movement Assessment Battery for Children - Second edition (MABC-2) and the Inventory of Lifestyle in Childhood and Adolescence (ILCA) were used. Lifestyle was analyzed with basis on specific tasks performed frequently or infrequently at home and outdoor, considering children with positive and negative DCD signs. Results: Only the item "performing household tasks" showed a significant association $(p=0.04)$ between groups. Children with DCD signs displayed a more infrequent behavior $(73.1 \%)$ in performing such tasks when compared to those without (26.9\%). Conclusion: Children with DCD signs presented a more sedentary behavior, expressed specifically in the less frequent performance of household tasks. The result may be explained by parental involvement in this sort of task. Further studies, however, are needed in order to broaden this understanding.
\end{abstract}

Keywords: physical activity, motor disorders, sedentary lifestyle, life habits.

\section{Introduction}

Motor coordination allows different movements to be performed with precision ${ }^{1}$. Such ability enables each person to carry on a vast range of daily activities with functionality $^{2}$. Not all individuals, however, always manage to coordinate their body movements at the same time and in the same way as their peers ${ }^{3}$. This motor limitation or disorder has a relevant impact on the life of many children, and when this coordination disorder interferes in their daily life, at school, and in their leisure activities, it is then possible to classify it with the nomenclature Developmental Coordination Disorder (DCD) ${ }^{4}$.

The term DCD is used in the international literature to refer to a significant motor coordination disorder that affects children from an early age and limits them in different daily activities but does not present correlations with cerebral palsy or autism ${ }^{4}$. Children affected by DCD are generally slower or experience greater difficulty in performing different motor activities, such as tying shoelaces, writing, bicycling or running, when compared to their peers without $\mathrm{DCD}^{5,6}$.

Due to all these limitations, and along with the frustration deriving from successive errors in tasks which other children manage to perform in a shorter time and with greater precision, children with DCD commonly isolate themselves from the others, avoiding the exposition of group activities ${ }^{6-8}$ and tend to seek activities in which they may feel more competent, like the more sedentary ones ${ }^{9}$.

Generally speaking, watching television and playing videogames are the most frequent activities in the leisure routine of children with DCD since they can be performed alone as well as do not require physical effort or motor abilities that are complex for their motor condition ${ }^{10}$. Given the sedentary behavior of these children, strategies encouraging them to explore their competence in an environment that motivates and strengthen their resistance to frustrating situations related to errors should be stimulated and applied at school age, once it is when the exploration of such motor abilities, still scarcely experimented, happens ${ }^{11}$.

Considering school environment as an interactional space for children, it is where male and female children begin to explore their bodily movements in a more elaborated manner and start to use many of those learned in their daily lives, once they begin to give a meaning to previously meaningless motor acts. Besides, the motor exploration within the classroom through writing, drawing, and cutting, the other school spaces offer to children a meaningful effort of movement coordination involving 
large muscle groups, such as running, jumping, or playing ballgames ${ }^{11}$.

School, therefore, is an environment of great relevance to determine children's lifestyle, since school activities may have a deep influence on a more or less physically active tendency of each child, depending on the manner they are performed. Along with school, the family is crucial for the habits of children and how they explore different physical activities and engage in more or less active games or tasks during the day ${ }^{12}$.

Given the importance of a physically active lifestyle, mainly from childhood, enhancing the engagement of school-aged children in activities with greater energetic expenditure will bring many benefits to their health and quality of life ${ }^{9}$, and will certainly stimulate appropriate health behavior that will remain for their whole existence. Despite the importance of motor coordination for a more active lifestyle, there are few studies published analyzing the association between lifestyle and motor coordination impairment (DCD signs) in school-aged children. Thus, this study aimed to analyze the association between lifestyle and DCD signs in children aged 7 to 10 .

\section{Methods}

It is a cross-sectional study, applied in four elementary schools of the city of São Carlos, State of São Paulo, Brazil, private or public. The schools were selected by convenience, since they had to be at a maximum $10 \mathrm{~km}$ distance from the university where the research was developed, in order to optimize the displacement of the researchers to the places, as well as considering the possibility of children identified as being affected by DCD to take part in future intervention projects at the same university, which could be logistically unfeasible for families residing in more remote places. The study was carried out between March 2016 and March 2018.

This study observed all Ethical precepts involving research on human beings, based on the Helsinki Declaration and on the 466/12 Resolution of the Health National Council/ Ministry of Health of Brazil. It was previously submitted to the Ethical Committee for Research on Human Beings of the Federal University of São Carlos, and approved with 47091115.0.0000.5504 CAEE number. All parents and/or guardians of voluntary children signed the Informed Consent Form, and all children signed the Consent Term.

\section{Participants}

Children aged 7 to 10 , enrolled in the elementary schools selected for the study, were the target audience. The $95 \%$ confidence interval was considered for sample size calculation with an $80 \%$ power for the Developmental Coordination Disorder (DCD) outcomes among students, adopting $10 \%$ prevalence as reference for DCD signs for the $\leq 16$ cut-off score of MABC-2 total score about the reference population of 300 students. The minimum calculated sample consisted of 74 children. In all, 93 children were recruited and assessed by all data collection instruments in this study.

\section{Inclusion and exclusion criteria}

Children whose parents/guardians signed the Informed Consent Form and who had correctly filled in the Developmental Coordination Disorder Questionnaire (DCDQ), Brazilian version ${ }^{13}$ of DCD screening and were present at school in the visiting days for data collection with the application of the Movement Assessment Battery for Children - Second Edition (MABC-2) were included in the study ${ }^{14}$.

Children showing physical, sensorial or intellectual deficits, as well as those with a diagnosis of autism or genetic syndromes, orthopedic problems or other conditions interfering in the performance of MABC-2 were excluded. With this intention, such information could be reported in specific assessment forms delivered to Informed Consent Form in order for the parents/guardians to fill them in.

\section{Outcomes and instruments}

DCD signs

Children were firstly evaluated through their parents' perception using the Developmental Coordination Disorder Questionnaire (DCDQ). With this instrument, parents/guardians evaluated signs indicative of DCD in children by responding 15 questions with answers ranging from 1 to 5 , in which they should compare the motor behaviors of their children with those of children of the same age group. Lower scores correspond to greater chances of the children to show signs of DCD, thus making them potential subjects for more specific motor evaluation. Children were classified with basis on the sum of the score of the 15 questions starting from the following cut-off points: total score $<46$ for children aged 7 , total score $<$ 55 for children aged between 8 and 9 and 11 months or total score $<57$ for children aged $10^{13}$.

\section{Motor impairments}

Children with the indicative classification of DCD through DCDQ had their motor coordination assessed directly with the Movement Assessment Battery for Children - Second edition (MABC-2), which is a group of standardized tests regarded as the golden standard ${ }^{15}$ to identify motor impairment related to DCD in school-aged children, and evaluates three domains: 1- Manual Dexterity; 2 - Aim \& Catching; 3 - Balance, divided into three different age bands: 1 - Children aged 3 to $6 ; 2$ - Children aged 7 to $10 ; 3$ - Children aged 11 to 16 . In this study, we used the tasks corresponding to aged 7 to 10 , 
three for manual dexterity, two for aim \& catching and three for balance. The performance of the children in the study allows the sum of specific punctuations whose scores are standardized and based on age range, allowing a final classification including total and standardized scores and percentiles. Children below the fifth percentile are classified as affected by DCD-related motor impairment; those with the percentile between 6 and 16 are classified as at risk of being affected by DCD-related motor impairment and those above percentile 16 are regarded as free from motor impairment. Original measures of the test reveal a $0.64-0.97$ test-re-test reliability values and 0.70 inter-evaluator reliability ${ }^{14}$. Children classified with $\leq 16^{\circ}$ percentile were named $\mathrm{DCD}+$, while those classified with $>16^{\circ}$ were named DCD- in the present study.

Lifestyle

For the evaluation of children's lifestyle, the Inventory of Lifestyle in Childhood and Adolescence, a standardized instrument to investigate children's habits, including the main activities performed at home and outdoor, was used. The Inventory of Lifestyle in Childhood and Adolescence consists of 17 questions and can be administered directly on children aged 7 to 14 . In this study, the version adapted to the Brazilian context was adopted ${ }^{16}$ and applied on children with $\mathrm{DCD}^{17}$, and children's lifestyle was divided into 1 - Activities at home, and 2 - Outdoor activities. The responses for each of the activities were dichotomized in 1 - Frequent, when the activity was reported by the children themselves, and 2 - Infrequent, when they did not report the activity as part of their daily habits.

\section{Procedures}

Initially, schools were visited to explain the aims and procedures of the study. Further visits to each classroom of the eligible participants of the research were done once authorization was conceded by the principal of each school, after being previously scheduled. In these visits, the Informed Consent Form was delivered along with the DCDQ and an explanatory sheet of paper of the study containing all the instructions needed in order to fill in the material. This same material was then collected to check that it was filled correctly and to verify the possible consent of the parents regarding children's participation through the signature of Informed Consent Form.

In total, 863 questionnaires were delivered in four schools, and 509 of these returned with the children, 361 of them being considered valid for being filled properly and with the Informed Consent Form signed by their responsible. Out of the 361 potentially eligible children for the study, 103 showed indicative classification of DCD via DCDQ and were suitable for MABC-2 assessment, once six children were transferred to other schools and four were out of the age group target of the study.
MABC-2 assessment was applied individually in a reserved room of each of the participating schools, away from noise and obstacles. Previously to the application, children responded to the Inventory of Lifestyle in Childhood and Adolescence in the form of an interview in the same room where the test was applied. This moment was important to facilitate the communication and interaction of the evaluator with the children, making the procedures of the test as natural and comfortable as possible. The whole procedure of administration of Inventory of Lifestyle in Childhood and Adolescence and MABC-2 lasted about 30 minutes per children, and all research procedures are described in Figure 1.

\section{Statistical analysis}

The chi-square test was applied to compare the proportion of children with (DCD+) and without (DCD-) DCD displaying frequent and infrequent behaviors at home and outdoor. The 5\% significance level was used as a reference for all comparisons. Odds ratio analysis was also applied through the Odds Ratio (OR) with a 95\%, confidence interval $(\mathrm{CI})$, considering DCD+ and DCDgroups as dependent variables of the study and the activities performed at home and outdoor as independent variables.

\section{Results}

The final sample consisted of 93 children, 52 of which $(55.91 \%)$ presented motor impairment indicating DCD $(8.36 \pm 0.79$ years, $66 \%$ male); 41 children $(44.09 \%)$ did not present motor impairment (aged $8.68 \pm$ $0.87,34 \%$ male).

As indicated in Table 1, only the performance of household tasks, among all activities performed at home by the children, was associated with the fact that the children were affected by DCD $(p=0.04$; OR $=0.35$; CI: 0.13 $0.96)$.

No significant differences were observed between groups of children with and without DCD for the outdoor activities performed, investigated in this study and listed in Table 2.

\section{Discussion}

An association was found in children between lifestyle and signs of DCD. A significant difference was found, specifically in activities at home only for the item "performance of household tasks". Children with DCD signs showed a significantly lower frequency of participation in this type of tasks when compared with their peers without such signs.

Considering the context of the commonly expected lifestyle for school-aged children, attention is drawn to the association found in the present study. Considering the 


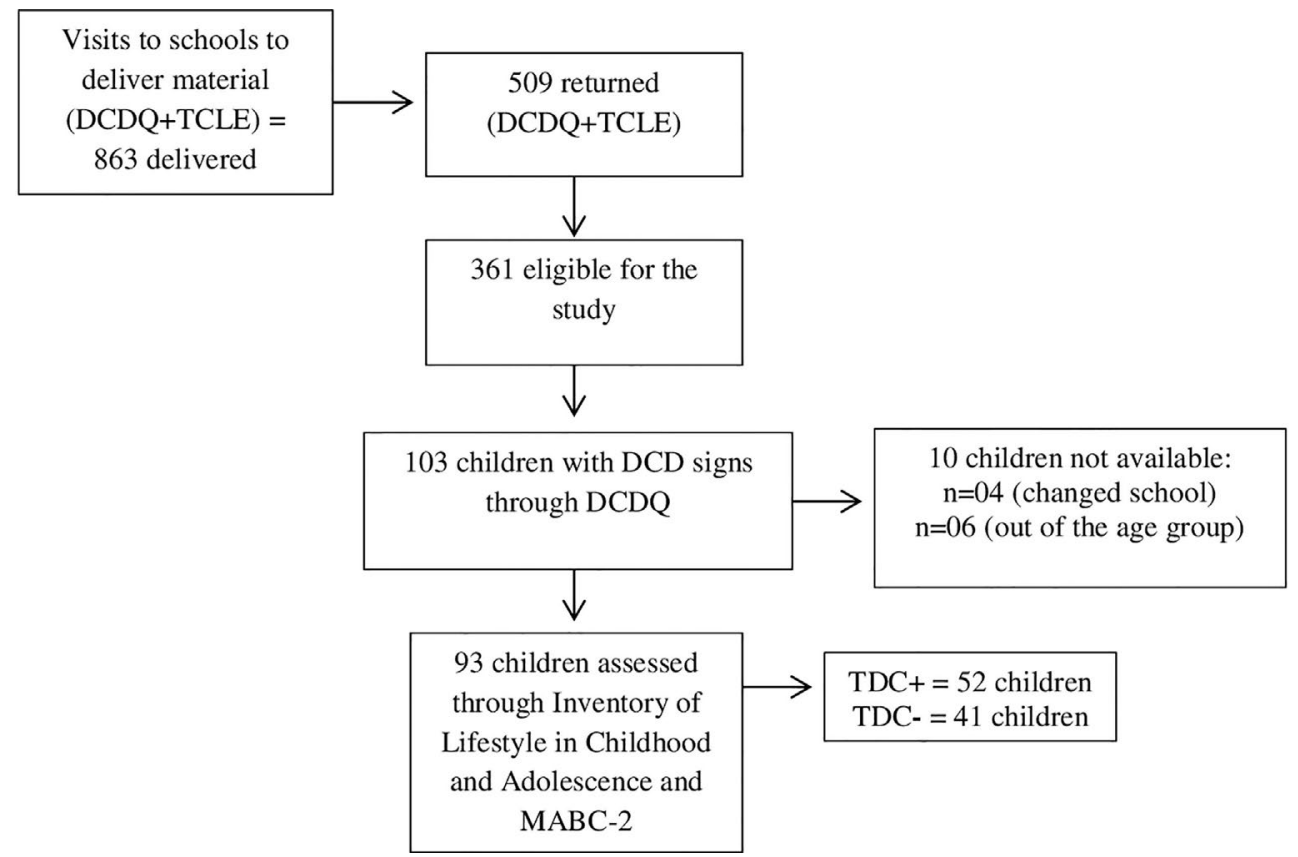

Figure 1 - Flowchart of the data collection procedures performed in this study.

Table 1 - Analysis of the association between lifestyles through the activities performed at home and positive or negative DCD classification among students.

\begin{tabular}{|c|c|c|c|c|c|}
\hline Activities at home & $\mathrm{DCD}+\mathrm{n}(\%)$ & DCD- n (\%) & Total n (\%) & p-value & OR (CI: 95\%) \\
\hline \multicolumn{6}{|l|}{ Watching TV } \\
\hline Frequent & $46(57.5)$ & $34(42.5)$ & $80(100)$ & & \\
\hline Infrequent & $06(46.2)$ & $07(53.8)$ & $13(100)$ & 0.44 & $1.57(0.48-5.12)$ \\
\hline \multicolumn{6}{|c|}{ Playing Videogames } \\
\hline Frequent & $21(60.0)$ & $14(40.0)$ & $35(100)$ & & \\
\hline Infrequent & $31(53.4)$ & $27(46.6)$ & $58(100)$ & 0.53 & $1.30(0.55-3.05)$ \\
\hline \multicolumn{6}{|l|}{ Leisure reading } \\
\hline Frequent & $36(55.4)$ & $29(44.6)$ & $65(100)$ & 0.87 & $0.93(0.38-2.27)$ \\
\hline Infrequent & $16(57.1)$ & $12(42.9)$ & $28(100)$ & & \\
\hline \multicolumn{6}{|l|}{ Listening to music } \\
\hline Frequent & $29(50.9)$ & $28(49.1)$ & $57(100)$ & 0.22 & $0.58(0.24-1.37)$ \\
\hline Infrequent & $23(63.9)$ & $13(36.1)$ & $36(100)$ & & \\
\hline \multicolumn{6}{|c|}{ Talking/playing with friends } \\
\hline Frequent & $26(56.5)$ & $20(43.5)$ & $46(100)$ & 0.90 & $1.05(0.46-2.38)$ \\
\hline Infrequent & $26(55.3)$ & $21(44.7)$ & $47(100)$ & & \\
\hline \multicolumn{6}{|c|}{ Talking/playing alone } \\
\hline Frequent & $24(51.1)$ & $23(48.9)$ & $47(100)$ & & \\
\hline Infrequent & $28(60.9)$ & $18(39.1)$ & $46(100)$ & 0.34 & $0.67(0.29-1.52)$ \\
\hline \multicolumn{6}{|l|}{ Household tasks } \\
\hline Frequent & $33(49.3)$ & $34(50.7)$ & $67(100)$ & & \\
\hline Infrequent & $19(73.1)$ & 07 (26.9) & $26(100)$ & 0.04 & $0.35(0.13-0.96)$ \\
\hline \multicolumn{6}{|c|}{ Parents' professional tasks } \\
\hline Frequent & $01(50.0)$ & $01(50.0)$ & $02(100)$ & 0.86 & $0.78(0.04-12.93)$ \\
\hline
\end{tabular}


Table 1 - continued

\begin{tabular}{|c|c|c|c|c|c|}
\hline Activities at home & $\mathrm{DCD}+\mathrm{n}(\%)$ & DCD- n $(\%)$ & Total n (\%) & p-value & OR (CI: 95\%) \\
\hline Infrequent & $51(56.0)$ & $40(44.0)$ & $91(100)$ & & \\
\hline \multicolumn{6}{|c|}{ Taking care of younger children } \\
\hline Frequent & $13(54.2)$ & $11(45.8)$ & $24(100)$ & 0.84 & $0.90(0.35-2.31)$ \\
\hline Infrequent & $39(56.5)$ & $30(43.5)$ & $69(100)$ & & \\
\hline \multicolumn{6}{|l|}{ Studying } \\
\hline Frequent & $45(58.4)$ & $32(41.6)$ & $77(100)$ & & \\
\hline Infrequent & $07(43.8)$ & $09(56.2)$ & $16(100)$ & 0.28 & $1.80(0.61-5.36)$ \\
\hline
\end{tabular}

Table 2 - Analysis of the association between lifestyles through the activities performed at home and positive or negative DCD classification among students

\begin{tabular}{|c|c|c|c|c|c|}
\hline Outdoor Activities & $\mathrm{DCD}+\mathrm{n}(\%)$ & DCD- n (\%) & Total n (\%) & p-value & OR (CI: 95\%) \\
\hline \multicolumn{6}{|l|}{ Going to the cinema } \\
\hline Frequent & $17(58.6)$ & $12(41.4)$ & $29(100)$ & 0.72 & $1.17(0.48-2.85)$ \\
\hline Infrequent & $35(54.7)$ & $29(45.3)$ & $64(100)$ & & \\
\hline \multicolumn{6}{|c|}{ Talking or playing with friends } \\
\hline Frequent & $15(60.0)$ & $10(40.0)$ & $25(100)$ & 0.63 & $1.25(0.49-3.19)$ \\
\hline Infrequent & $37(54.4)$ & $31(45.6)$ & $68(100)$ & & \\
\hline \multicolumn{6}{|l|}{ Playing alone } \\
\hline Frequent & $04(44.4)$ & $05(55.6)$ & $09(100)$ & 0.46 & $0.60(0.15-2.39)$ \\
\hline Infrequent & $48(57.1)$ & $36(42.9)$ & $84(100)$ & & \\
\hline \multicolumn{6}{|l|}{ Taking a walk } \\
\hline Frequent & $07(46.7)$ & $08(53.3)$ & $15(100)$ & 0.43 & $0.64(0.21-1.94)$ \\
\hline Infrequent & $45(57.7)$ & $33(42.3)$ & $78(100)$ & & \\
\hline \multicolumn{6}{|l|}{ Travelling by car } \\
\hline Frequent & $29(50.0)$ & $29(50.0)$ & $58(100)$ & 0.14 & $0.52(0.21-1.24)$ \\
\hline Infrequent & $23(65.7)$ & $12(34.3)$ & $35(100)$ & & \\
\hline \multicolumn{6}{|c|}{ Going to the park/square } \\
\hline Frequent & $23(52.3)$ & $21(47.7)$ & $44(100)$ & 0.50 & $0.75(0.33-1.71)$ \\
\hline Infrequent & $29(59.2)$ & $20(40.8)$ & $49(100)$ & & \\
\hline \multicolumn{6}{|l|}{ Bicycling } \\
\hline Frequent & $28(50.9)$ & $27(49.1)$ & $55(100)$ & 0.24 & $0.60(0.26-1.40)$ \\
\hline Infrequent & $24(63.2)$ & $14(36.8)$ & $38(100)$ & & \\
\hline \multicolumn{6}{|l|}{ Rollerskating } \\
\hline Frequent & $12(46.2)$ & $14(53.8)$ & $26(100)$ & 0.24 & $0.57(0.23-1.44)$ \\
\hline Infrequent & $40(59.7)$ & $27(40.3)$ & $67(100)$ & & \\
\hline \multicolumn{6}{|l|}{ Skating } \\
\hline Frequent & $07(53.8)$ & $06(46.2)$ & $13(100)$ & 0.87 & $0.90(0.28-2.94)$ \\
\hline Infrequent & $45(56.2)$ & $35(43.8)$ & $80(100)$ & & \\
\hline \multicolumn{6}{|l|}{ Playing ballgames } \\
\hline Frequent & $34(63.0)$ & $20(37.0)$ & $54(100)$ & 0.10 & $1.98(0.85-4.58)$ \\
\hline Infrequent & $18(46.2)$ & $21(53.8)$ & $39(100)$ & & \\
\hline \multicolumn{6}{|c|}{ Going to the shopping mall } \\
\hline Frequent & $41(57.7)$ & $30(42.3)$ & $71(100)$ & 0.52 & $1.36(0.52-3.56)$ \\
\hline Infrequent & $11(50.0)$ & $11(50.0)$ & $22(100)$ & & \\
\hline \multicolumn{6}{|l|}{ Going to parties } \\
\hline Frequent & $00(00)$ & $02(100)$ & $02(100)$ & 0.19 & - \\
\hline Infrequent & $52(57.1)$ & $39(42.9)$ & $91(100)$ & & \\
\hline
\end{tabular}


fact that children displaying low motor proficiency (DCDrelated) showed a more sedentary lifestyle ${ }^{17,18}$ and lower participation in group activities ${ }^{6,7}$, there was an expectation for a similar lower frequency in participation in outdoor activities, specifically related to the use of sporting and leisure equipment, such as bicycling, skating or playing ballgames. However, no meaningful differences were found about these tasks for the population studied.

It was also expected from children with DCD signs to present a more frequent performance of individual tasks, such as watching TV, playing videogames or playing alone. As documented in the literature, the preference for sedentary games and activities are frequent in children with motor coordination difficulties, including those with $\mathrm{DCD}^{6,19}$.

A Brazilian study ${ }^{17}$ performed with children and young students aged between 11 and 13, with and without DCD, found a significant association between the use of videogames and the likely classification of DCD in children with the use of Inventory of Lifestyle in Childhood and Adolescence. Similarly, another Brazilian study ${ }^{20}$ performed with school children aged between 9 and 12 found that those affected by psychomotor problems spent most of their leisure time with electronic and sedentary activities, such as playing videogames, watching TV and using the internet on a computer.

In addition, we could consider that the children in the present study follow a world trend independent from conditions of DCD, since they do not attain satisfactory levels of physical activity and cultivate more sedentary lifestyles, even at school age ${ }^{21}$. Despite some higher frequencies in many sedentary activities, such as playing videogames or watching television, no significant differences were found between children with and without DCD signs in the present study.

Using the characteristics of household tasks, such as tidying the room, cleaning the house, gardening, etc., as a reference, we may suppose that there is a certain parental involvement in this relation. Children are commonly encouraged by their parents and older siblings, and mirror their actions when taking care of the house as well, contributing to the performance of household chores with the members of their family.

Regarding the influence of the family on children's behavior, a study performed in China ${ }^{22}$ with 7.286 secondary school students indicated that families involved in the practice of physical activities favor their children to adopt a physically active lifestyle, minimizing their sedentary behavior. Another study ${ }^{23}$ performed in Canada with 102 pre-school-aged children found greater motivation for the development of physical activity among those with more parental support. The children with more parental support had six times higher chances of maintaining a physically active lifestyle than those with lower parental support $^{23}$. Our findings, even indirectly, reinforce the indi- cations in literature ${ }^{24}$ regarding the importance of families in the process of identification of motor alterations in children.

Considering that the sedentary behavior and the preference for electronic activities may be regarded as a risk behavior for $\mathrm{DCD}^{25,26}$, more detailed observation on parents and children, as well as greater involvement in physical activities (even in household tasks) with their children may reduce future motor problems and help in giving a direction to specific interventions. The association found in this study about household tasks may indicate different perspectives for the comprehension of the profile of the lifestyle of children affected by DCD.

\section{Limitations}

As a limitation, it is worth highlighting the fact that this study has a descriptive and cross-sectional design. Hence, many other issues may have not been addressed in it, such as the deeper investigation of the relationship between parents and children, the characteristics of the school environment, the physical levels and the performance of these children in physical fitness tests. This could help to a better comprehension of our findings.

Furthermore, given the small sample proportion between public and private school, the choice was not to perform analysis of the association between lifestyle and type of school, because it could lead to mistakes in the interpretation and indicate less precise information due to the numerical imparity of children from the public $(\mathrm{n}=70)$ and private school $(\mathrm{n}=23)$. Despite the fact that the present study found significant associations for only one Inventory of Lifestyle in Childhood and Adolescence item, further and more detailed investigations about the lifestyle of Brazilian children with DCD should be performed. For example, an international study identified compromisement in all lifestyle categories through the life habits instrument (LIFE-H) ${ }^{6}$ in children with DCD. This reveals a great impact on the social participation of these children, with non-measurable damage, and can be an important starting point for this type of studies on Brazilian children.

\section{Conclusion}

Children with DCD signs showed a significant higher infrequent behavior (73.1\%) in the performance of household tasks when compared with their peers without such signs $(26.9 \%)$. Issues related to parental involvement, expressed in the performance of household tasks, may indicate potential explaining factors and should be investigated in future studies. 


\section{Acknowlegdments}

We would like to thank FAPESP - Fundação de Amparo à Pesquisa do Estado de São Paulo, grant number 2015/ 24291-0.

\section{References}

1. Lopes VP, Stodden DF, Bianchi MM, Maia JAR, Rodrigues LP. Correlation between BMI and motor coordination in children. J Sci Med Sport. 2012;15(1):38-43. doi:10.1016/j. jsams.2011.07.005

2. Corbin C, Pangrazi R, Franks B. Definitions: health, fitness, and physical activity. Pres Counc Phys Fit Sport Res Dig. 2000;3:1-11.

3. Summers J, Larkin D, Dewey D. Activities of daily living in children with developmental coordination disorder: Dressing, personal hygiene, and eating skills. Hum Mov Sci. 2008;27(2):215-229. doi:10.1016/j.humov.2008.02.002

4. American Psychiatric Association. Diagnostic Stat Man Ment Disord DSM-5. 2013. dsm.psychiatryonline.org.

5. Schoemaker MM, van der Wees M, Flapper B, Verheij-Jansen N, Scholten-Jaegers S, Geuze RH. Perceptual skills of children with developmental coordination disorder. Hum Mov Sci. 2001;20(1-2):111-133.

6. Sylvestre A, Nadeau L, Charron L, Larose N, Lepage C. Social participation by children with developmental coordination disorder compared to their peers. Disabil Rehabil. 2013;35(21):1814-1820. doi:10.3109/ 09638288.2012 .756943

7. Mandich AD, Polatajko HJ, Rodger S. Rites of passage: understanding participation of children with developmental coordination disorder. Hum Mov Sci. 2003;22(4-5):583595. http://www.ncbi.nlm.nih.gov/pubmed/14624835. Accessed December 3, 2017.

8. Engel-Yeger B, Hanna Kasis A. The relationship between Developmental Co-ordination Disorders, child's perceived self-efficacy and preference to participate in daily activities. Child Care Health Dev. 2010;36(5):670-677. doi:10.1111/ j.1365-2214.2010.01073.x

9. Raz-Silbiger S, Lifshitz N, Katz N, Steinhart S, Cermak SA, Weintraub N. Relationship between motor skills, participation in leisure activities and quality of life of children with Developmental Coordination Disorder: Temporal aspects. Res Dev Disabil. 2015;38:171-180. doi:10.1016/j. ridd.2014.12.012

10. Cairney J, Hay JA, Faught BE, Wade TJ, Corna L, Flouris A. Developmental Coordination Disorder, Generalized SelfEfficacy Toward Physical Activity, and Participation in Organized and Free Play Activities. J Pediatr. 2005;147 (4):515-520. doi:10.1016/j.jpeds.2005.05.013

11. Katartzi ES, Vlachopoulos SP. Motivating children with developmental coordination disorder in school physical education: The self-determination theory approach. Res Dev Disabil. 2011;32(6):2674-2682. doi:10.1016/j. ridd.2011.06.005

12. Stuntz CP, Weiss MR. Motivating Children and Adolescents to Sustain a Physically Active Lifestyle. Am J Lifestyle Med. 2010;4(5):433-444. doi:10.1177/1559827610368779
13. Prado M, Magalhães L, Wilson B. Cross-cultural adaptation of the Developmental Coordination Disorder Questionnaire for brazilian children. Brazilian J Phys Ther. 2009;13 (3):236-243. doi:10.1590/S1413-35552009005000024

14. Henderson SE, Sugden DA, Barnett A. Movement Assessment Battery for Children - Second Edition. 2007. https:// www.pearsonclinical.com/therapy/products/100000433/ movement-assessment-battery-for-children-second-editionmovement-abc-2.html.

15. Venetsanou F, Kambas A, Ellinoudis T, Fatouros I, Giannakidou D, Kourtessis T. Can the Movement Assessment Battery for Children-Test be the "gold standard" for the motor assessment of children with Developmental Coordination Disorder? Res Dev Disabil. 2011;32(1):1-10. doi:10.1016/j. ridd.2010.09.006

16. Cardoso LT e, Gaya A. Hábitos de vida de alunos de uma escola da rede municipal de ensino de Porto Alegre. Rev Perf. 1997;1(1):24-37.

17. Contreira AR, Capistrano R, Oliveira A do VP de, Beltrame TS. Lifestyle in children with and without developmental coordination disorder. Fisioter e Pesqui. 2014;21(3):223228. doi:10.590/1809-2950/48921032014

18. Faught BE, Hay JA, Cairney J, Flouris A. Increased risk for coronary vascular disease in children with developmental coordination disorder. J Adolesc Heal. 2005;37(5):376-380. doi:10.1016/j.jadohealth.2004.09.021

19. Rivilis I, Hay J, Cairney J, Klentrou P, Liu J, Faught BE. Physical activity and fitness in children with developmental coordination disorder: A systematic review. Res Dev Disabil. 2011;32(3):894-910. doi:10.1016/j.ridd.2011.01.017

20. Lucena NMG de, Lucena LC de, Aragão POR de, Melo LGB de, Rocha T do V, Andrade SM. Relação entre perfil psicomotor e estilo de vida de crianças de escolas do município de João Pessoa, PB. Fisioter e Pesqui. 2010;17(2):124129. doi:10.1590/S1809-29502010000200006

21. Colley RC, Garriguet D, Adamo KB, Carson V, Janssen I, Timmons BW, et al. Physical activity and sedentary behavior during the early years in Canada: a cross-sectional study. Int J Behav Nutr Phys Act. 2013;10(1):54. doi:10.1186/1479-5868-10-54

22. Wang X, Liu Q-M, Ren Y-J, Lv J, Li L-M. Family influences on physical activity and sedentary behaviours in Chinese junior high school students: a cross-sectional study. BMC Public Health. 2015;15:287. doi:10.1186/s12889-0151593-9

23. Zecevic CA, Tremblay L, Lovsin T, Michel L. Parental Influence on Young Children's Physical Activity. Int J Pediatr. 2010;2010:468526. doi:10.1155/2010/468526

24. Cavalcante Neto JL, Sato T de O, Tudella E. Socio-demographic factors influences on guardians' perception of Developmental Coordination Disorder among Brazilian schoolchildren. Mot Rev Educ Física. 2018;24(2):e101810. doi:10.1590/s1980-6574201800020002

25. Cairney J, Hay JA, Faught BE, Wade TJ, Corna L, Flouris A. Developmental Coordination Disorder, Generalized SelfEfficacy Toward Physical Activity, and Participation in Organized and Free Play Activities. J Pediatr. 2005;147 (4):515-520. doi:10.1016/j.jpeds.2005.05.013 
26. Cairney J, Hay J, Faught B, Mandigo J, Flouris A. Developmental Coordination Disorder, Self-Efficacy Toward Physical Activity, and Play: Does Gender Matter? Adapt Phys Act Q. 2005;22(1):67-82. doi:10.1123/apaq.22.1.67

\section{Corresponding author}

Jorge Lopes Cavalcante Neto Departamento de Ciências Humanas, Curso de Educação Física, Avenida J.J. Seabra, s/n, Estação, Jacobina, Bahia, Brasil.

E-mail: jorgelcneto@hotmail.com.
Manuscript received on July 20, 2019

Manuscript accepted on February 17, 2020

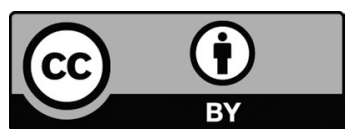

Motriz. The Journal of Physical Education. UNESP. Rio Claro, SP, Brazil - eISSN: 1980-6574 - under a license Creative Commons - Version 4.0 